Çukurova Üniversitesi Mühendislik Mimarlık Fakültesi Dergisi, 35(4), ss. 835-845, Aralık 2020

\title{
Elektrik Kontak Kesicilerde Kullanabilmek için Aşınma Dirençli Polimer ve Polimer Kompozit Malzemelerin Belirlenmesi
}

\author{
Hüseyin ÜNAL ${ }^{* 1}$, Salih Hakan YETGİN ${ }^{2}$ \\ ${ }^{1}$ Sakarya Uygulamalı Bilimler Üniversitesi, Teknoloji Fakültesi, Metalurji ve Malzeme \\ Mühendisliği Bölümü, Sakarya \\ ${ }^{2}$ Tarsus Üniversitesi, Mühendislik Fakültesi, Makine Mühendisliği Bölümü, Mersin
}

Geliş tarihi: 01.07.2020 Kabul tarihi: 30.12 .2020

\section{$\ddot{\mathbf{O z}}$}

Bu çalışma, elektrik sektöründe kontak kesicilerde aşınma direnci en iyi olan malzeme çiftini belirlemek için yapılmıştır. Aşınma deneyleri için pim-disk aşınma test cihazı kullanılmıştır. Bunun için çalışmada, disk malzemesi olarak \%25 oranında uzun cam elyaf takviyeli ve $\% 40$ kalsiyum karbonat katk1lı doymamıs polyester esaslı termoset kompozit malzeme $\left(\% 25 \mathrm{CE}+\% 40 \mathrm{CaCO}_{3}+\mathrm{UPET}\right)$ kullanılmıștır. Pim malzemeler olarak ise, katkısız poli-eter-sülfon (PES) polimeri, stiren-butadien-stiren elastomer katkılı ve $\% 30$ cam elyaf takviyeli poli-fenilen-eter ( $\mathrm{PPE}+\mathrm{SBS}+\% 30 \mathrm{CE}$ ) kompoziti ve $\% 15$ cam elyaf takviyeli poli-butilen-tereftalat/poli-etilen-tereftalat karışımı kompozit (PBT/PET+\%15CE) malzemeleri kullanılmıştır. Tribolojik deneyler, kuru kayma şartları altında ve oda sıcaklığında gerçekleştirilmiştir. Deneyler, $0,707,1,415,2,123$ ve 3,538 MPa basınç altında ve $0,5 \mathrm{~m} / \mathrm{s}$ kayma hızında yapılmıştır. Aşınma ve sürtünme deneyleri sonucunda, malzemelerin sürtünme katsayısı ve spesifik aşınma hızları belirlenmiştir. Gerçekleştirilen deneyler sonucunda, en yüksek aşınma hızı katkısız PES polimerinde elde edilirken en düşük aşınma hızı ise PPE+SBS+\%30CE kompozitinde elde edilmiştir. Gerçekleştirilen deneyler sonucunda kontak kesicilerde kullanmak için PPE+SBS+\%30CE/\%25CE+\% $40 \mathrm{CaCO}_{3}+\mathrm{UPET}$ termoset kompozit çifti en uygun malzeme çifti olarak belirlenmiştir.

Anahtar Kelimeler: Temoplastik, Termoset, Aşınma, Polimer, Kompozit

\section{Determination of Polymer and Polymer Composites with Wear Resistant for Use in Electrical Contact Breaker}

\begin{abstract}
This study was carried out to determine the pair of materials with the best abrasion resistance in contact breakers in the electrical industry. Pin-on-disk wear test machine was used for tribological tests. For this purpose, $25 \mathrm{wt} . \%$ long glass fiber reinforced and 40wt.\% calcium carbonate added unsaturated polyester based thermoset composite material $\left(25 \mathrm{wt} . \% \mathrm{GF}+40 \mathrm{wt} . \% \mathrm{CaCO}_{3}+\mathrm{UPET}\right)$ was used as the disc material. As pin materials, unfilled poly-ether-sulfone (PES) polymer, 30wt.\% glass fiber reinforced poly-
\end{abstract}

*Sorumlu yazar (Corresponding author): Hüseyin ÜNAL, unal@subu.edu.tr 
phenylene-ether (PPE+SBS+30wt.\%GF) composite and 15wt.\% glass fiber reinforced poly-butyleneterephthalate/poly-ethylene-terephthalate mixture composite (PBT/PET+15wt.\%GF) materials were used. Tribological experiments were carried out under dry sliding conditions and at room temperature. The experiments were carried out under pressure of $0.707,1.415,2.123$ and $3.538 \mathrm{MPa}$ and at a sliding speed of $0.5 \mathrm{~m} / \mathrm{s}$. As a result of wear and friction tests, friction coefficient and specific wear rates of materials used were determined. As a result of the experiments carried out, the highest wear rate was obtained in the unfilled PES polymer, while the lowest wear rate was obtained in PPE+SBS+30wt.\%GF composite. As a result of the experiments carried out, PPE + SBS $+30 \mathrm{wt} . \% \mathrm{GF} / 25 \mathrm{wt} \% \% \mathrm{GF}+40 \mathrm{wt} . \% \mathrm{CaCO}_{3}+\mathrm{UPET}$ thermoset composite pair has been determined as the most suitable material pair for use in contact breakers.

Keywords: Thermoplastic, Thermoset, Wear, Polymer, Composite

\section{GÍRIŞ}

Plastikler günlük yaşantımızın vazgeçilmez malzemelerinden birisidir. Son yıllarda geleneksel malzemeler olan ahşap, metal, seramik ve demir dışı malzemelerin yerini hızla almaktadır. Bunun sebebi ise hafiflik, renklendirilebilme, kimyasallara direnç, elektriksel yalıtkanlık, kolay şekillendirilme ve düşük maliyet gibi özeliklerdir. Yüksek performanslı mühendislik termoplastiklerinden birisi olan poli-eter-sülfon (PES) polimeri amorf yapıya sahip olup, üstün kimyasal kararlılık, yüksek 1sıl direnç, yüksek mukavemet ve elastiklik modülü, $180^{\circ} \mathrm{C}$ 'ye kadar çalışma sıcaklığı, yüksek yanmayı geciktiricilik özelliği ile elektriksel yalıtım gibi mükemmel özelliğe sahiptir. Bu yüksek performanslar göz önüne alındığında, poli-eter-sülfon polimeri otomobil, elektrik-elektronik, havacılık, mikroelektronik gibi endüstrilerde yaygın olarak kullanım alanı bulmaktadır [1-6]. Bu özelliklere ilave olarak PES polimeri, nispeten yüksek sürtünme katsayısı ve aşınma oranı gibi özelikler göstermektedir [2]. Daha önce yapılan çalışmalarda, PES polimerinin kuru kayma koşullarında yüksek sürtünme katsayısı ve aşınma oranı gösterdiği gözlenmiştir [7-9].

Poli-etilen-tereftalat (PET) ve poli-bütilentereftalat (PBT) polimerleri de çok önemli ticari yarı-kristal termoplastik poliester polimerleridir. PET polimeri, düşük maliyetli olmasıyla PBT termoplastik polyesterine göre üstün özellikleri gösterir. Bu özelliği ile en yaygın kullanılan ticari polyesterdir. PET, ayrıca, mükemmel termal ve mekanik özelliklere, yüksek kimyasal dirence, yüksek şeffaflığa, oksijen ve su buharına karşı iyi bariyer özelliklerine sahiptir. $\mathrm{Bu}$ özelliklerinden dolayı PET, tekstil elyafları, meşrubat şişeleri, ambalaj filmleri, gibi gida endüstrisinde, otomotiv yapısal bileşenlerinde, makine imalat sektörü ve elektrik/elektronik sanayinde endüstriyel parçaların üretiminde yaygın olarak kullanılmaktadır. Poli-bütilen-tereftalat polimeri de ticari aromatik bir termoplastik polyester çeşididir. PBT, yüksek sıcaklıklarda iyi boyutsal kararlılık, düşük su emme, yüksek rijitlik ve çekme mukavemeti gibi mekanik özellikler, kimyasal bozunmaya karşı iyi direnç, gibi özeliklere sahiptir [10-12]. Bu özellikleri ile PBT günümüzde elektrik/elektronik, otomotiv ve mekanik uygulamalar gibi endüstriyel alanlarda kullanılmaktadır. Katkısız PET ve PBT polyesterleri benzer kimyasal yapıya sahip olmalarından dolayı üretim esnasında uyumlaştırıcıya gerek kalmadan birbirleriyle kolaylıkla karıştırılabilmektedir. Belirli oranlarda karıştırılan PET/PBT karışımları, işlenebilirliği, yüzey kalitesini, 1sıl deformasyon sicaklığını (HDT), darbe dayanımını ve boyutsal kararlılık özelliklerini geliştirmektedir. PET/PBT karışımları, yüksek rijitlik ve mukavemet, yüksek 1sıl ve kimyasal direnç ile tribolojik özellikleri ile ev araç-gereçlerinin üretiminde, elektrik ve otomotiv sektöründe farklı uygulamalarda kullanım alanını sürekli olarak artırmaktadır [11-12].

Poli-fenilen-eter (PPE) polimeri, $207^{\circ} \mathrm{C}$ gibi yüksek camsı geçiş sıcaklığı, düşük su emme, iyi 
boyutsal kararlılık ve yüksek süneklik gibi özelliklere sahip amorf bir mühendislik polimeridir. PPE polimerinin yüksek yumuşama sıcaklığ1 ve yüksek ergiyik viskozitesi nedeniyle üretim zorluğu ve ayrıca zayıf çözücü direnci gibi dezavantajları da mevcuttur. Yüksek sıcaklıklara dayanıklı olması sebebiyle geleneksel enjeksiyon makinaları ile üretimi zor olup fiyatının da yüksek olması dezavantajlı yönleridir [14-16]. Polistiren (PS) ve PPE polimerlerinin termodinamik olarak karışabilirliği olduğundan PPE/PS karışımları son y1llarda endüstriyel olarak en iyi bilinen polimer karışımı haline gelmiştir. PPE polimeri aynı zamanda poliamitler [16,17], poli-etilen-tereftalat (PET) [18], polipropilen (PP) [19] ve yüksek yoğunluklu polietilen [14] polimerleri ile de kullanılabilmektedir.

\section{2. ÖNCEKİ ÇALIŞMALAR}

Harshavardhan ve arkadaşları [20] kısa karbon fiber miktarının PES polimerinin termal özelliklerine etkisini incelemişlerdir. Karbon fiber ilave edilmesi ile PES/Karbon fiber kompozitin 1s1l iletkenliği artmış ve \%30 karbon fiber içeriğinde $0,238 \mathrm{~W} / \mathrm{m}^{\circ} \mathrm{K}$ elde edilmiştir. Çalışma sonucunda, \%30 karbon fiber katkılı PES polimerinin yüksek mukavemet ve iletkenlik gerektiren rulmanlar, burçlar gibi uygulamalarda faydalı olabileceği belirtilmiştir. Marek [12] ekstrüzyon ve enjeksiyon kalıplama yöntemi ile değişik oranlarda $(100 / 0$; 95/5; 90/10;80/20; 70/30; 50/50;25/75; 0/100) ürettikleri PET/PBT karışımlarının mekanik ve termal özelliklerini incelemiştir. PET/PBT karışımlarının özellikle darbe dayanımını arttığını belirtmiştir. Çalışmasında artan PBT polimer oranının artması ile kristallenme sicaklığının azaldığı, kristallenme oranının ise arttı̆̆ belirtilmiştir. Benzer şekilde Aravinthan ve Kale [10] farklı oranlardaki $(100 / 0 ; 80 / 20 ; 70 / 30 ; 60 / 40$; 50/50; 40/60; 20/80; 0/100) PET/PBT karışımların mekanik, termal, elektriksel ve reolojik özelliklerini incelemişlerdir. Katkısız PET ve PBT'ye göre tüm karışımların yüksek darbe dayanımı gösterdiği belirtilmiştir. PBT ilave edilmesi ile PET'in işlenebilirliği artmıştır. Tüm karışımlar için tek bir camsı geçiş sıcaklığı piki elde edilmiştir. Karışımların ergime sıcaklığı değişmezken artan PBT miktarı ile camsı geçiş sıcaklığı azalmıştır. PBT ilavesi ile arıza geriliminin azaldığı belirtilmiştir. Hazer ve arkadaşları [13] indirgenmiş grafen oksit katkılı PET/PBT karışımı kompozitleri ergiyik karıştırma yöntemi ile üretmişler ve kompozitlerin mekanik, termal ve termo-mekanik özelliklerini incelemişlerdir. Kompozitteki grafen oksit miktarının artmasına bağlı olarak PET/PBT karışımının kristallenme oranı ve ergime sıcaklığı artmıştır. Aynı zamanda, artan grafen oksit miktarı ile kopma uzaması azalırken çekme dayanımının hafif şekilde değiştiği belirtilmiştir. Endüstriyel uygulamalarda bazı kullanım alanlarında katkısız polyester kullanılırken mukavemet istenen alanlarda ise cam elyaf takviyeli polyesterlerin kullanımı ön plana çıkmıştır. Literatürde yapılan araştırmalar neticesinde, özellikle son yıllarda polietersülfon, cam elyaf takviyeli ve stirenbutadien-stiren elastomer katkılı poli-fenilen-eter kompozitleri ve cam elyaf takviyeli poli-butadientereftalat/poli-etilen-tereftalat karışımı kompozit malzemelerin aşınma ve sürtünme davranışları üzerine pek çalışmaya rastlanmamıştır. Buna ilaveten yukarıdaki malzemelerin karşı disk malzemesi olan doymamış polyester kompozit kullanımı üzerine çalışmaya da rastlanmamıştır. Ancak katkısız polyester ve cam elyaf takviyeli termoset polyester esaslı malzemelerin aşınma davranışları farklı ortam şartları ve parametreler altında deneysel olarak incelendiği gözlenmiştir. Polimer esaslı kompozitlerin sürtünme ve aşınma davranışları uygulanan yük, kayma hızı, kayma mesafesi gibi test parametrelerine bağlıdır. Yingjun ve arkadaşları [21] poli-fenilen-sülfit (PPS), poli-eter-sülfon (PES) ve poli-sülfon (PSU) polimerlerinin aşınma ve sürtünme davranışlarını incelemişlerdir. Çalışmalarında kullandıkları yükün $(25-250 \mathrm{~N})$ ve hızın $(0,1-0,6 \mathrm{~m} / \mathrm{s})$ artmas1 ile PPS polimeri maksimum sürtünme katsayısı $(0,96)$ değeri gösterirken PES ve PSU polimerlerinin sürtünme katsayısı değerlerinde hafif bir şekilde azalma gözlenmiştir. Yüksek yük ve kayma hızlarında PPS polimerinin aşınma oranı PES ve PSU polimerlerinden daha düşük elde edilmiştir. Sürtünme ve aşınma özelliklerini 
etkileyen en önemli parametrenin ısıya karşı gösterdikleri direnç olduğunu belirtmişlerdir. Amorf PES ve PSU polimerlerinin sürtünme yüzeyleri yumuşadığı zaman, sıvı gibi davranarak karşı yüzeye yapışarak düşük sürtünme özelliği göstermektedir. Kristal yapılı PPS polimeri ise yüksek mekanik özellikler ve sıcaklıklara dayanıklı olduğu için benzer sıcaklıklarda katı madde gibi davranarak yük taşıyabilirlik özelliği gösterir. $\mathrm{Bu}$ özellik PES ve PSU polimerlerine göre PPS polimerine daha yüksek aşınma direnç özelliği sağlamaktadır. Shicheng ve arkadaşları [2] genleştirilmiş grafitten elde ettikleri nano-boyutlu grafit oksit (GO) katkılı Poli-eter-sülfon (PES) polimerinin mekanik, termal ve tribolojik performanslarını incelemişlerdir. GO ilave edilmesi ile PES kompozitlerin mekanik ve termal özellikleri artmıştır. Katkısız PES polimeri ile karşılaştırıldığında PES/GO kompozitinin sürtünme katsayısının azaldığı, aşınma direncinin arttığ 1 belirtilmiştir. \%0,6 GO ilavesinde en düșük sürtünme katsayısı $(0,17)$ ve aşınma oranı $\left(1,07 \times 10^{-14} \mathrm{~m}^{3} / \mathrm{N} . \mathrm{m}\right)$ elde edilmiştir. Yan ve arkadaşları [22] ise Sodyum-Montmorillonit (NaMMT) nanopartikül katkılı PES/Politetrafloretilen (PTFE) polimerinin tribolojik özelliklerini incelemişlerdir. Çalışma sonucunda, ağırlıkça \%10 Na-MMT içeren PES/PTFE kompozitin optimum sürtünme ve aşınma performansı gösterdiğini belirtmişlerdir. PES/PTFE karışımı ile karşılaştırıldığında sürtünme katsayısı \%19,1 ve aşınma oranı ise \%97,2 oranında azalmıştır. Aşınma oranındaki azalmanın sebebi ise kendinden yağlamalı özelliğe sahip PTFE polimerinin oluşturduğu transfer film tabakası olarak açıklanmıştır. Mohit ve arkadaşları [8] karbon elyaf takviyeli farklı moleküler ağırlığa sahip PES polimerlerinin tribolojik özelliklerini incelemişlerdir. Çalışmaları sonucunda uygulanan yükün artması ile sürtünme katsayısı değeri azalırken aşınma oranının ise arttığı belirlenmiştir. Moleküler ağırlığın artması ile hem sürtünme katsayısının hem de aşınma oranının $\operatorname{arttı̆̆~}$ gözlenmiştir. Zhao ve arkadaşları'da [9] kısa karbon elyaf (KE) ve kısa cam elyaf (CE) takviyeli PES polimerinin mekanik ve tribolojik özelliklerini incelemişlerdir. Çalışma sonucunda karbon elyaf ve cam elyaf oranının artması ile kompozitin mekanik özelliklerinin arttığ1 belirtilmiştir. \%30 karbon elyaf takviyeli PES polimer kompozitinin sürtünme katsayısı $\% 48,8$ oranında artarak maksimum değere ulaşmıştır. Ancak, artan karbon elyaf oranının artması ile sürtünme katsayısı değerleri azalırken \%20 karbon elyaf takviyeli PES polimer kompozitinin sürtünme katsayısında \%29,8 oranında maksimum azalma elde edilmiştir. PES polimerinin aşınma oranı karbon elyaf ve cam elyaf ilavesi ile azalmıştır. \%20 KF ve CF ilavesinde PES polimer kompozitlerin aşınma oranları yaklaşık olarak sırasıyla $\% 71$ ve $\% 95$ oranlarında azaldığ belirtilmiştir. Georgescu ve arkadaşları [23] cam küre, karbon siyahı, PTFE ve aramid fiber katkılı PBT kompozitlerin tribolopjik özelliklerini incelemişlerdir. Çalışma sonucunda, \%10 aramid fiber takviyeli PBT kompozitin en düşük aşınma değerleri gösterdiğini ve uygulanan kayma hızı aralıklarında $(0,25 \mathrm{~m} / \mathrm{s}-0,75 \mathrm{~m} / \mathrm{s})$ çok düşük hassasiyete sahip olduğunu belirtmişlerdir.

$\mathrm{Bu}$ çalışmanın amacı, elektrik sektöründe kontak kesicilerde kullanabilmek amaciyla gerçekleştirilen tribolojik deneyler sonucunda en iyi aşınma dirençli ve en ekonomik olan polimer çiftini belirlemektir. Çalışmada, vazgeçilmez olan ve mutlaka kullanılması gereken $\% 25$ oranında uzun cam elyaf takviyeli ve $\% 40$ oranında kalsiyum karbonat katkılı doymamış polyester termoset kompozit malzemesi seçilmiş ve üretilmiştir. $\mathrm{Bu}$ malzeme, deneylerde karşı disk malzeme olarak kullanılmıştır. Polyester kompozit malzemeye alternatif olacak ve onunla en iyi tribolojik performansı gösterecek üç farklı polimer ve polimer kompozit malzeme seçilmiştir. Seçilen bu malzemeler, poli-eter-sülfon polimeri, stiren butadien stiren elastomer katkılı $\% 30$ oranında cam elyaf takviyeli poli-fenilen-eter polimer kompoziti ve $\% 15$ oranında k1sa cam elyaf takviyeli poli-butilen-tereftalat/poli-etilen-teretalat polimer karışımı kompozitidir. Tribolojik deneyler, 0,707, 1,415, 2,123 ve 3,538 MPa basınç altında ve kuru kayma şartlarında yapılmış olup, sürtünme katsayısı ve spesifik aşınma oranı belirlenmiştir. Çalışma sonucunda, elektrik 
sektöründe kontak kesicilerde kullanılabilecek en uygun aşınma dirençli ve ekonomik malzeme çifti belirlenmiştir.

\section{MATERYAL VE METOT}

Bu deneysel çalışmada, karşı disk malzeme olarak $\% 25$ uzun cam elyaf takviyeli ve \%40 kalsiyum karbonat katkılı doymamış polyester esaslı termoset kompozit malzemesi (\%25CE+\%40CaCO3+UPET) kullanılmıştır (Şekil 1). Aşınma ve sürtünme deneylerinde ağırlık olarak \%40 oranında kalsiyum karbonat ve \%25 oranında uzun cam elyaf takviyeli termoset polyester esaslı kompozit malzeme, karşı disk malzeme olarak kullanılmış olup mutlaka kullanılması gereken ve vazgeçilmez özelliği olan bir malzemedir. Karşı disk malzemeyi üretmek için Poliya Polyester, İstanbul firmasından doymamış polyester satın alınmıştır. $13 \mu \mathrm{m}$ çaplı ve $12 \mathrm{~mm}$ boyundaki uzun cam elyaflar, Cam Elyaf Sanayi, İstanbul'dan, $10 \mu \mathrm{m}$ partikül boyutlu kalsiyum karbonat dolgu maddesi ise OMYA Madencilik firması, İstanbul'dan temin edilmiștir. Pim malzeme olarak ise katkısız polietersülfon (PES) polimeri, Stiren-butadien-stiren (SBS) elastomer katkılı ve \%30 cam elyaf takviyeli polifenilen-eter (PPE+SBS+\%30CE) kompoziti ve $\% 15$ cam elyaf takviyeli poli-butadientereftalat/poli-etilen-tereftalat karışımı kompozit (PBT/PET+\%15CE) malzemeleri kullanılmıştır. Deneylerde kullanılan polimer ve polimer kompozitlerin fiziksel, mekanik, termal ve elektriksel özellikleri Çizelge 1 'de verilmiştir.

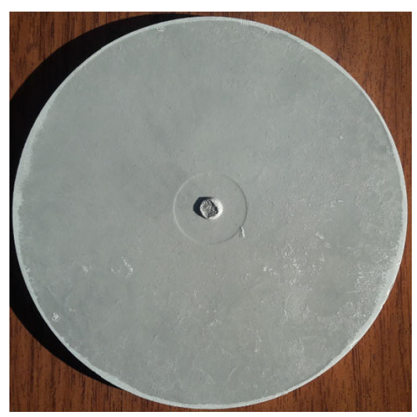

Şekil 1. $\% 25 \mathrm{CE}+\% 40 \mathrm{CaCO}_{3}+\mathrm{UPET}$

kompozit karşı disk

Aşınma deneyleri, ASTM G99 standardına uygun olarak pim-disk aşınma cihazında ve kuru ortam şartlarında gerçekleştirilmiştir. Deneylerde kullanılan termoplastik pim malzemeler, özel olarak imal edilmiş enjeksiyon kalıpları kullanılarak ERAT marka bir enjeksiyon makinası kullanılarak $6 \mathrm{~mm}$ çapında ve $50 \mathrm{~mm}$ uzunluğunda olacak şekilde kalıplanmıştır. Enjeksiyonla kalıplama işleminden önce matris malzemeleri $120^{\circ} \mathrm{C}$ firın ortamında 4 saat süre ile kurutulmuştur. Enjeksiyon makinesinde ise numune proses şartlarına uygun olarak basılmıştır. Tribolojik testlerde, karşı disk malzeme olarak ağırlık olarak \%25 oranında uzun cam elyaf takviyeli ve $\% 40$ oranında kalsiyum karbonat katkılı doymamış polyester termoset kompozit malzemesi kullanılmıştır.

Çizelge 1. Deneylerde kullanılan polimer ve polimer kompozitlerin fiziksel, mekanik, termal ve elektriksel özellikleri

\begin{tabular}{|l|c|c|c|}
\hline Özellikler & Katk1sız PES & PPE+SBS+\%30CE & PBT/PET+\%15CE \\
\hline Yoğunluk $\left(\mathrm{g} / \mathrm{cm}^{3}\right)$ & 1,37 & 1,26 & 1,43 \\
\hline Çekme mukavemeti $(\mathrm{MPa})$ & 90 & 110 & 90 \\
\hline Elastiklik modülü $(\mathrm{MPa})$ & 2700 & 9000 & 5000 \\
\hline Darbe mukavemeti, $\left(\mathrm{kj} / \mathrm{m}^{2}\right)$ & 7 & 4 & 6 \\
\hline Ergime sıcaklığ $\left({ }^{\circ} \mathrm{C}\right)$ & - & - & 225 \\
\hline Heat deflection temperature, $1,8 \mathrm{MPa}\left({ }^{\circ} \mathrm{C}\right)$ & 75 & 141 & 175 \\
\hline Nem emme $(\%)$ & 0,7 & 0,3 & 0,06 \\
\hline Dielektrik mukavemeti $(\mathrm{KV} / \mathrm{mm})$ & 37 & 90 & - \\
\hline Yüzey direnci $(\mathrm{ohm})$ & $>1 \times E 15$ & $1 \times \mathrm{xE14}$ & - \\
\hline Dielektrik sabiti $(1 \mathrm{MHz})$ & 3,8 & 2,9 & - \\
\hline CTI & 100 & - & $\mathrm{HB}$ \\
\hline Yanmazlık sınıfi, $1,5 \mathrm{~mm}(\mathrm{UL} 94)$ & $\mathrm{V} 0$ & $\mathrm{HB}$ & \\
\hline
\end{tabular}


Disk malzemeler ise $100 \mathrm{~mm}$ çapında ve $5 \mathrm{~mm}$ kalınlığında olacak şekilde yine hacim kalıplama tekniği (BMC) ile sıcak preste üretilmiştir. Doymamıs polyester esaslı termoset kompozitler, bir elektrik imalat parçaları üreten bir firmanın desteği ile firma bünyesindeki cihaz ve makinalar kullanılarak üretilmiştir. Termoset esaslı polyester kompozitler üretmek için önce doymamış polyester akışkanlığı sağlayıcı stiren ile 100:25 oranında karıştırılmıştır. Sonra çapraz bağlama ajanı olarak metil-etil-keton-peroksit (MEKP), geciktirici olarak BC500, stabilizatör olarak çinko sterat ve yoğunlaştırıcı olarak ise magnezyum oksit, viskozite azaltıcı ve renklendiricilerin tamamı 10 dakika süre ile karıştırıcıda karıştırılmıștır. Sonrasında elde edilen hamur karışımı Z-tipi bir karıştıııcıya alınıp kalsiyum karbonat ilave edilerek yarım saat, daha sonra da uzun cam elyaflar ilave edilerek 15 dakika karıştırılmıştır. Hazırlanan hamur karışımı, karşı disk malzeme üretmeden önce 7 gün boyunca şartlandırılmıştır. Disk malzemeler $120 \mathrm{~mm}$ çaplı ve $10 \mathrm{~mm}$ kalınlığında olacak şekilde kalıpta $1500 \mathrm{MPa}$ basınç altında, $150^{\circ} \mathrm{C}$ sicaklıkta 60 saniye boyunca kürlenmiştir. Aşınma ve sürtünme deneylerinden önce, pim polimer malzemeler ve karşı malzeme disk yüzeyleri 1200 nolu zımpara ile zımparalanmıştır. Her test öncesinde hem disk yüzeyleri hem de pim yüzeyleri asetonla temizlenip kurutulmuştur.

Şekil 2'de tribolojik testlerin gerçekleştirildiği çalışma ortamı ve pim-disk aşınma cihazının şematik resmi verilmiştir. Aynı zamanda deneylerde kullanılan termoplastik esaslı polimerlerinin tribolojik deneylerin proses şartları Çizelge 2'de verilmiştir. Bir elektrik motorunun tahriği ile dönen diskin üzerine deneylerde kullanılan disk malzemeler bir vida yardımıyla sabitlenmiștir. Kol üzerinde bulunan bir mekanizma ile $6 \mathrm{~mm}$ çapındaki polimer pim malzemeler de kola bir bağlama aparatı ile bağlanır. Makine çalıştırıldığında, pim numunesinin diske sürtünmesiyle pim numunesinin bağlı olduğu kol aparatı da diskin dönme yönüne hareket etmek istemektedir. $\mathrm{Bu}$ ileriye doğru olan hareket yanal kuvveti vermektedir. Bu yanal kuvvet ise bir yük hücresi (Load-cell) ile ölçülmüştür. Alınan veriler aynı zamanda direk bilgisayarda Excel programında depolanmıştır. Deneylerde dakikada 1000 yanal yük verisi alınmış ve deneylerde kullanılan yüke bölünerek Excel programında grafik haline getirilmiștir.
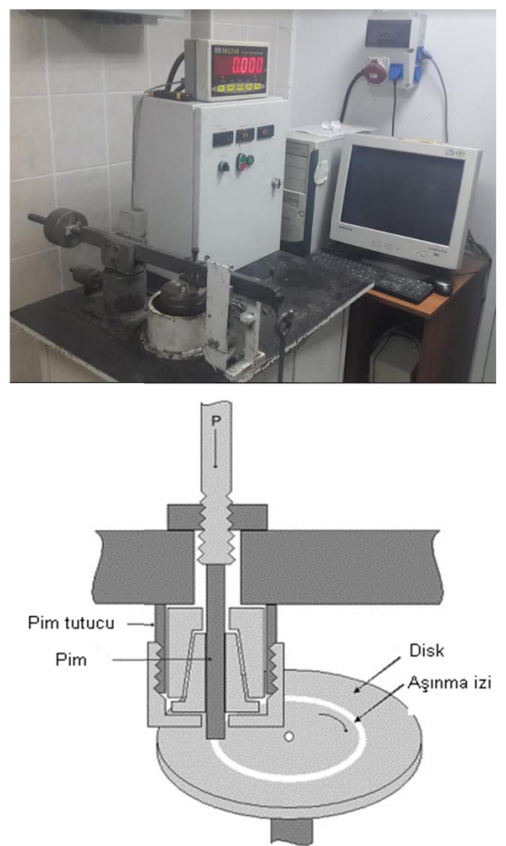

Şekil 2. Çalışma ortamı ve pim-disk aşınma test cihazı şematik gösterimi

Çizelge 2. Deneylerde kullanılan polimer ve kompozit malzemelerin tribolojik test şartları

\begin{tabular}{|c|c|c|c|c|c|}
\hline Malzeme & $\begin{array}{l}\text { Test Sicaklı̆̆ } 1 \\
\left({ }^{\circ} \mathrm{C}\right)\end{array}$ & $\begin{array}{l}\text { Kayma mesafesi } \\
(\mathrm{m})\end{array}$ & $\begin{array}{r}\mathrm{H} 1 \mathrm{z} \\
\left(\mathrm{m} \mathrm{s}^{-1}\right)\end{array}$ & $\begin{array}{c}\text { Uygulanan yük } \\
(\mathrm{MPa})\end{array}$ & $\operatorname{Nem}(\%)$ \\
\hline Katkısız PES & \multirow{4}{*}{$21 \pm 1$} & \multirow{4}{*}{1000} & \multirow{4}{*}{0,5} & 0,707 & \multirow{4}{*}{$31 \pm 3$} \\
\hline $\mathrm{PPE}+\mathrm{SBS}+\% 30 \mathrm{CE}$ & & & & 1,415 & \\
\hline PBT/PET+\%15CE & & & & 2,123 & \\
\hline & & & & 3,538 & \\
\hline
\end{tabular}


Sürtünme katsayısı yanal kuvvetin, normal uygulanan kuvvete oranı olarak ifade edilir ve Eşitlik 1 ile hesaplanır. Burada, $\mu$ : Sürtünme katsayısını, FS: Yanal sürtünme kuvveti $(\mathrm{N})$ ve FN ise Normal kuvveti $(\mathrm{N})$ ifade eder.

$$
\mu=\frac{F_{S}}{F_{N}}
$$

Her bir aşınma testinden önce ve sonra kompozit pimlerim ağırlıkları ölçülmüş ve ağırlık kaybı $(\Delta \mathrm{m})$ tespit edilmiştir. Eşitlik 2'de formül kullanılarak, aşınma test numunelerinin spesifik aşınma hızları $\left(\mathrm{K}_{0}\right)$ hesaplanmıştır. Spesifik aşınma hız1;

$$
K_{o}=\frac{\Delta m}{L * \rho * F}
$$

Burada; $\Delta \mathrm{m}$ : ağırlık kaybı (g), L: kayma mesafesi (m), $\rho$ : malzemenin yoğunluğu $\left(\mathrm{g} / \mathrm{cm}^{3}\right), \quad F$ : uygulanan yük $(\mathrm{N})$.

\section{DENEY SONUÇLARI}

Şekil 3'de katkısız PES polimeri ile $\mathrm{PPE}+\mathrm{SEBS}+\% 30 \mathrm{CE}$ ve $\mathrm{PBT} / \mathrm{PET}+\% 15 \mathrm{CE}$ kompozitlerin $0,5 \mathrm{~m} / \mathrm{s}$ kayma hızında artan basınca bağlı olarak sürtünme katsayılarındaki değişim verilmiştir. Şekilde görüldüğü gibi deneylerde kullanılan tüm polimer ve polimer kompozitlerin sürtünme katsayısı değerleri uygulanan basıncın artması ile artmaktadır. Katkısız PES polimerinin sürtünme katsayısı 0,129 iken uygulanan basıncın artması ile birlikte artmış ve 3,53 $\mathrm{MPa}$ basınç altında $\quad 0,249$ değerine ulaşmıştır. $\mathrm{PPE}+\mathrm{SEBS}+\%$ 30CE kompozitinin sürtünme katsayısı incelendiğinde ise $0,707 \mathrm{MPa}$ basınç altında 0,056 olan sürtünme katsayısı, basıncın $\% 400$ oranında artırılması ile 0,098 değerine ulaşmıştır. PPE+SEBS+\%30CE polimer kompozitinin sürtünme katsayısı da uygulanan basınca bağlı olarak \%75 oranında artmıştır. $\mathrm{PBT} / \mathrm{PET}+\% 15 \mathrm{CE}$ polimer kompozitin sürtünme katsayıs1 ise uygulanan basincin 0,707 $\mathrm{MPa}$ dan 3,538 MPa'a artırılması ile \%46,7 oranında artmıştır. Sürtünme katsayısındaki artışın sebebi ise uygulanan basıncın artması ile birlikte abrasif aşınmanın baskın hale gelmessi ile açıklanabilir. Yani basıncın artması ile pim-disk gerçek temas yüzey alanının arttığı söylenebilir. 0,707 $\mathrm{MPa}$ basınç altında, katkısız PES polimerinin sürtünme katsayıs1 PPE+SEBS+\%30C'E kompozitinden $\% 152$ oranında, $\mathrm{PBT} / \mathrm{PET}+\% 15 \mathrm{CE}$ kompozitinden ise $\% 31$ oranında daha yüksek elde edilmiştir.

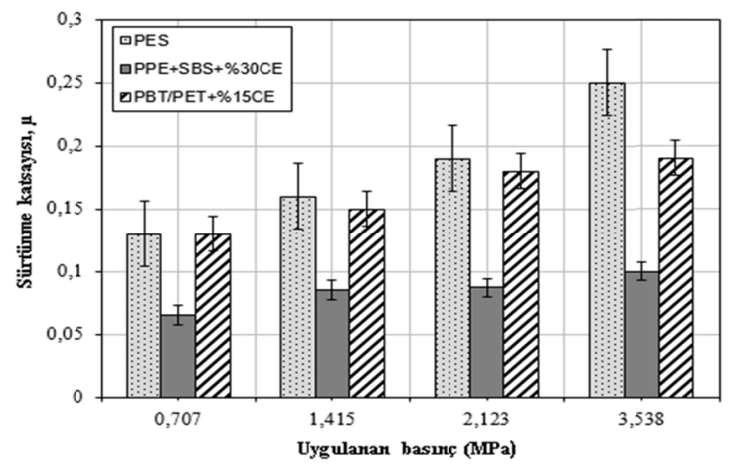

Şekil 3. PES, PPE+SEBS+\%30CE ve PBT/ PET+\%15CE kompozitlerin sürtünme katsayısı-uygulanan basınç ilişkisi (Hız: $0,5 \mathrm{~m} / \mathrm{s}$ )

Uygulanan basınç aralıklarında en yüksek sürtünme katsayısı 3,538 MPa basınç altında 0,249 değeri ile katkısız PES polimerinde elde edilirken en düşük sürtünme katsayısı $0,707 \mathrm{MPa}$ basınç altında 0,056 değeri ile PPE+SEBS+\%30CE kompozitinde elde edilmiştir. Katkısız PES polimerine göre cam elyaf takviyeli kompozit malzemelerin sürtünme katsayıları azalma göstermiştir. Bilindiği gibi, kompozit içerisindeki cam elyaf uygulanan basıncı karşılamaktadır ve temas alanını azaltmaktadır. Bu yüzden artan cam elyaf oranı ile kompozitlerin sürtünme katsayısı azalmaktadır. Bu sonuçlar da daha önce literatürde yapılan çalışmalarla uyum göstermektedir [24-27].

Şekil 4'te ise PES, PPE+SEBS+\%30CE ve $\mathrm{PBT} / \mathrm{PET}+\% 15 \mathrm{CE}$ kompozitlerin $0,5 \mathrm{~m} / \mathrm{s}$ kayma hızında artan basınca bağlı olarak spesifik aşınma oranlarındaki değişim verilmiştir. Genel olarak, PES, PPE + SEBS+\%30CE ve PBT/PET+\%15CE kompozitlerin spesifik aşınma oranı $10^{-14} \mathrm{~m}^{2} / \mathrm{N}$ olarak belirlenmiştir. En düşük aşınma oranı $1,96 \times 10^{-14} \mathrm{~m}^{2} / \mathrm{N}$ değeri ile $\mathrm{PPE}+\mathrm{SEBS}+\% 30 \mathrm{CE}$ 
kompozitinde elde edilirken en yüksek aşınma oranı $3,70 \times 10^{-14} \mathrm{~m}^{2} / \mathrm{N}$ değeri ile PES polimerinde elde edilmiştir. PES polimerinin aşınma oranı $\mathrm{PPE}+\mathrm{SEBS}+\%$ 30CE kompozitin aşınma oranından $\% 52$ oranında, PBT/PET+\%15CE kompozitin aşınma oranından ise \%38 oranında daha yüksek elde edilmiştir. Aşınma direncindeki bu artışın, polimerin deformasyonunu engelleyen ve kompozitin mekanik özelliklerini artıran cam elyaf mukavemet artırıcilar nedeniyle olduğu düşünülmektedir. Uygulanan 0,707-3,538 $\mathrm{MPa}$ basınç aralıklarında, katkısız PES, $\mathrm{PPE}+\mathrm{SEBS}+\% 30 \mathrm{CE}$ ve $\mathrm{PBT} / \mathrm{PET}+\% 15 \mathrm{CE}$ kompozitlerin aşınma oranı uygulanan basıncın artması ile artmıştır. Aşınma oranındaki bu artış, katkısız PES polimeri için \%68 oranında iken PPE+SEBS+\%30CE kompoziti için \%23, $\mathrm{PBT} / \mathrm{PET}+\% 15 \mathrm{CE}$ kompoziti için ise \%30 oranında elde edilmiştir. Uygulanan basıncın artması ile karşı yüzeye yapışma artmakta ve polimer yüzeyinden daha kolay partiküller kopmaktadır. Bu da uygulanan basıncın artması ile aşınma oranının artmasına sebep olmaktadır. Fakat katkısız PES polimerine göre polimer matris bünyesindeki cam elyaf katkılar kompozit malzemelerin çekme mukavemeti ve elastiklik modülünün artmasına yani rijitliğinin artmasına dolayısıyla kompozitlerin aşınma direncinin artmasına da sebep olmaktadır. Çizelge 1 ve Şekil 4. Elde edilen bu sonuçlar ve sebepler daha önce literatürde Mohit ve arkadaşları [8], Zhao ve arkadaşları [9] ve Yingjun ve arkadaşları [20]'nın yaptığı çalışmalarda elde ettiği sonuçlar ile uyum göstermektedir. Ana matris bünyesindeki cam elyaf oranının artması, kompozitlerin ağırlık kaybının kontrol edilmesinde önemli bir rol oynadığı ifade edilebilir. Ana polimer matris bünyesindeki cam elyaf oranının artması ile sürtünen yüzeyler arasındaki cam elyaflar kırılmakta ve aşınma miktarı artmaktadır ve düşük yüklerde bu kırılan cam elyaflar kayma süresince ara yüzeyden uzaklaşmaktadır. Ancak, uygulanan basıncin artması ile kirılan cam elyaflar daha küçük parçalara ayrılarak aşınma yüzeylerine (karşı disk malzeme veya pim polimer) yapışmaktadır. Bu durum ise hem yüzey sertliğinin ve rijitliğinin artmasına bunun sonucu olarak da daha düşük aşınma oranları elde edilmiştir Şekil 4-6. Elde edilen sonuçlar daha önce yapılan çalışmalarla uyum içindedir [24,27].

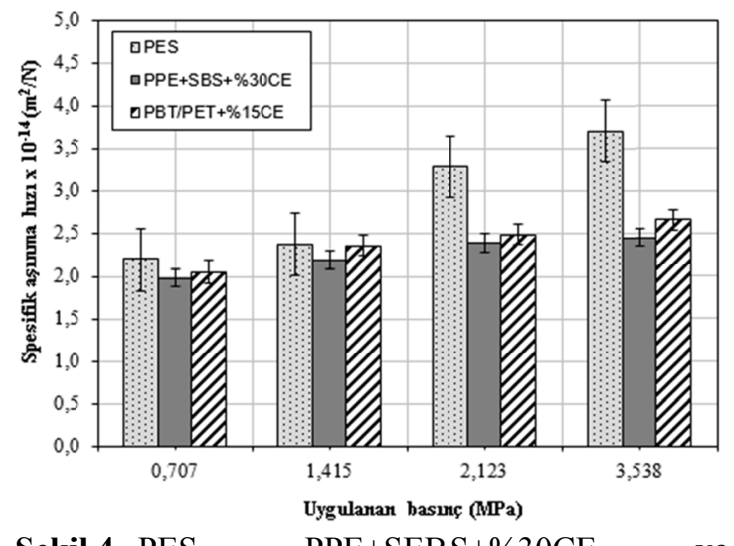

Şekil 4. PES, PPE + SEBS $+\%$ 30CE ve $\mathrm{PBT} / \mathrm{PET}+\%$ 15CE kompozitlerin spesifik aşınma oranı-uygulanan basınç ilişkisi (H1z: 0,5 m/s)

Şekil 5 (a,b) sırasıyla katkısız PES polimeri ile PPE+SEBS+\%30CE kompozitinin 3,538 $\mathrm{MPa}$ basınç altında ve $0,5 \mathrm{~m} / \mathrm{s}$ kayma hızında karşı disk malzeme ile çalışması durumunda elde edilen aşınma yüzeyinin optik mikroskopta alınan mikroyapı görüntüleri verilmiştir. Şekil $6(a, b)$ ise katkısız PES polimeri ve PPE+SEBS+\%30CE kompozitinin 3,538 MPa basınç altında ve $0,5 \mathrm{~m} / \mathrm{s}$ kayma hızında aşınma deneyine maruz kalması durumunda $\% 25 \mathrm{CE}+\% 40 \mathrm{CaCO}_{3}+\mathrm{UPET}$ kompozit karşı disk malzeme yüzeyinde elde edilen aşınma yüzeyinin optik mikroskopta alınan mikroyapı görüntüleri verilmiştir. Şekilde 5a dikkatli bir şekilde incelendiğinde katkısız PES polimerinin aşınma yüzeyinde derin ve geniş aşınma izleri tespit edilmiştir. Yani PES polimeri için abrazif aşınma mekanizması şeklinde bir aşınma gözlenmiştir. Karşı disk malzemesi olan $\% 25 \mathrm{CE}+\% 40 \mathrm{CaCO}_{3}+\mathrm{UPET}$ kompozit malzemesi bünyesindeki cam elyaflar katkısız PES polimerinin aşınma yüzeylerinde kazıyıcı etki yaparak abrazif aşınmasına sebep olmuştur. Karş1 disk malzemenin aşınma yüzeyinde ise PES polimerinden gelen aşınma partikülleri beyaz renkli ve yapışmış olarak görüınmektedir, Şekil 6a, 
Şekil 5b ise PPE+SEBS+\%30CE kompozitinin ve Şekil $6 \mathrm{~b}$ ise $\% 25 \mathrm{CE}+\% 40 \mathrm{CaCO}_{3}+\mathrm{UPET}$ karşı kompozit disk malzeme aşınma yüzeyinin birbirleriyle çalışması durumunda elde edilen optik mikroskop görüntülerini göstermektedir. Şekil 5b'de PPE+SEBS+\%30CE kompozitinin bünyesinde bulunan cam elyaflar karşı disk malzeme bünyesinde bulunan cam elyaflar ile temas ederek ana matris malzemenin aşınmasını önlemektedir. Katkısız PES polimerinin aşınma yüzey görüntüsünden farklı olarak
PPE + SEBS+\%30CE polimer kompozitin aşınma yüzeyinde daha az aşınma izleri ve düzgün bir yüzey olduğu gözlenmiştir. Yine Şekil 6b'de ise $\mathrm{PPE}+\mathrm{SEBS}+\% 30 \mathrm{CE} / \% 25 \mathrm{CE}+\% 40 \mathrm{CaCO}_{3}+\mathrm{UPET}$ karşı disk aşınma çiftinde karşı disk malzeme yüzeyinde de cam elyaf oranından dolayı daha az abrazif aşınma izleri görülmekttedir. Hatta yüzeyde kırılmış cam elyaflar malzeme yüzeyinde matris malzemeye yapışarak aşınma direncinin artmasına dolayısıyla daha az aşınmasına sebep olmaktadır (Şekil 4).

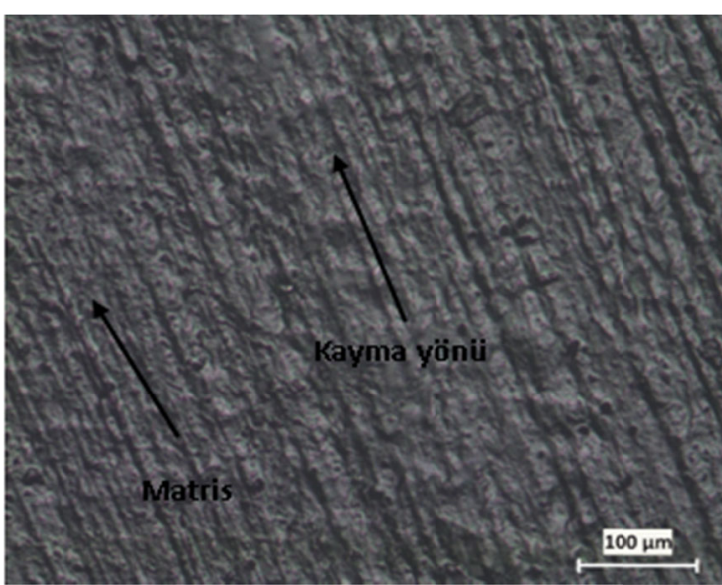

a) Katkısız PES polimer

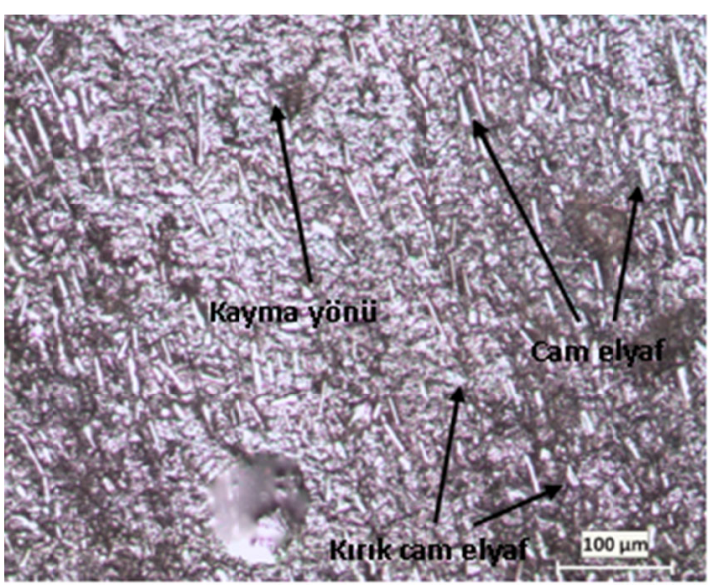

b) PPE+SEBS+\%30CE kompozit

Şekil 5. PES polimer ve PPE+SEBS+\%30CE kompozitin aşınma yüzeyi optik miikroskop mikroyap1 görüntüleri (Uygulanan basıç:3,538 MPa, Kayma hızı 0,5 m/s)

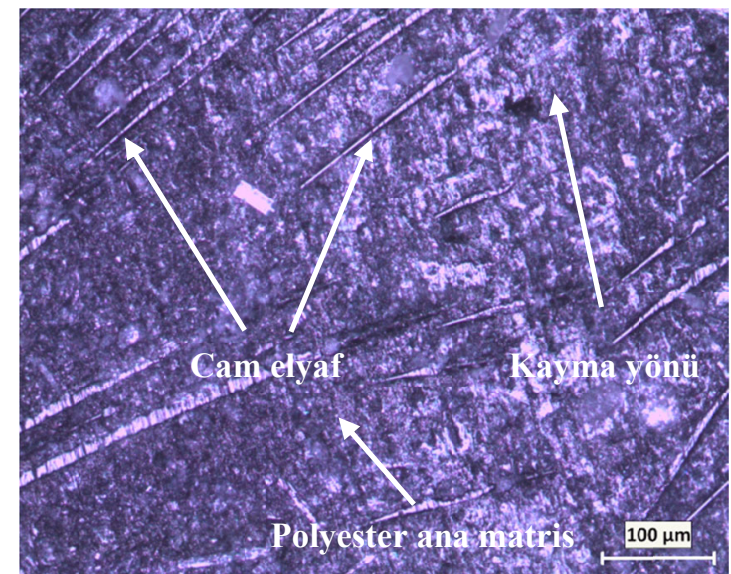

a) PES polimer

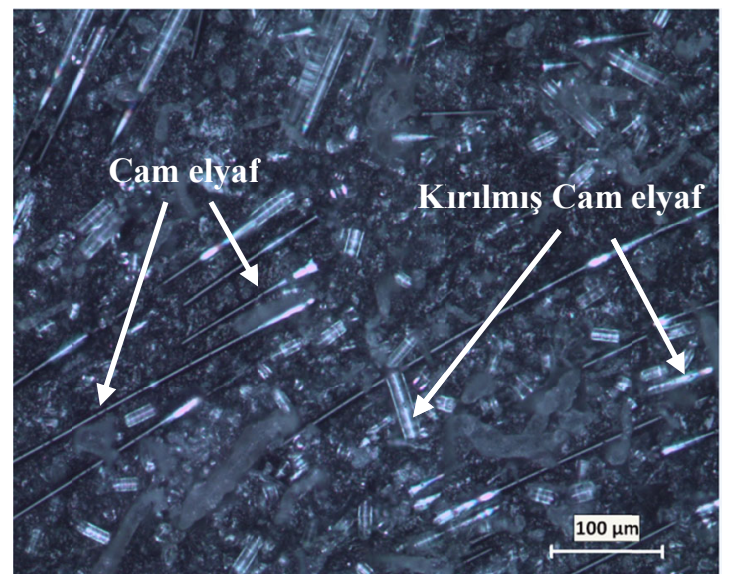

b) PPE+SEBS+\%30CE kompozit

Şekil 6. PES polimer ve PPE + SEBS +\%30CE kompozit ile çalışan diskin aşınma yüzeyi optik mikroskop mikroyapı görüntüleri (Uygulanan basınç: 3,538 MPa, Kayma hızı 0,5 m/s) 


\section{SONUÇLAR VE ÖNERILER}

$\mathrm{Bu}$ deneysel çalışmada, gerçekleştirilen deneyler sonucunda aşağıdaki sonuçlar elde edilmiştir.

Çalışmada kullanılan tüm polimer esaslı malzemelerin sürtünme katsayıları uygulanan basıncın artırılması ile artıș göstermektedir. En düşük sürtünme katsayısı $\mathrm{PPE}+\mathrm{SBS}+\% 30 \mathrm{CE}$ kompozitinde elde edilmiştir. En yüksek sürtünme katsayısı ise PES polimerinde elde edilmiştir. Deneylerde kullanılan her üç polimer malzeme için, spesifik aşınma hızları uygulanan yükün artması ile artış göstermiştir. Uygulanan basınç aralığında en düşük spesifik aşınma hızı yaklaşık olarak $1,96 \times 10^{-14} \mathrm{~m}^{2} / \mathrm{N}$ değeri ile $\mathrm{PPE}+\mathrm{SBS}+\%$ 30CE kompozitinde elde edilmiştir. En yüksek spesifik aşınma hızı ise ortalama $3,70 \times 10^{-14} \mathrm{~m}^{2} / \mathrm{N}$ değeri ile PES polimerinde elde edilmiştir. Doymamış polyester kompozit malzemesine göre elektrik endüstrisinde kontak kesicilerde kullanma amaçlı gerçekleştirilen çalışma neticesinde PPE $+\mathrm{SBS}+\% 30 \mathrm{CE}$ kompozit malzemesi en uygun malzeme olarak tespit edilmiştir. Deneylerde kullanılan malzemeler arasında PES polimerinin aşınma oranı PPE+SEBS+\%30CE kompozitin aşınma oranından \%52 oranında, PBT/PET+\%15CE kompozitin aşınma oranından ise $\% 38$ oranında daha yüksek elde edilmiştir. Sürtünme katsayısı ve spesifik aşınma hızları gözönüne alındığında PBT/PET+\%15CE kompoziti, PPE+SBS+\%30CE kompozitine göre daha ucuz olduğundan maliyet açısından PBT/PET+\%15CE kompozitinin seçilmesi daha uygun olduğuna karar verilmiştir.

\section{KAYNAKLAR}

1. Chunguang, L., Rongfeng, L., Yang, S., Manyu, H., Taishan, C., Wei, X., Xiaofeng, Y., 2011. Mechanical and Tribological Properties of PTW/PTFE/PPS/PES Composites. Advanced Materials Research, 284-286, 205-209.

2. Shicheng, Y., Yulin, Y., Laizhou, S., Xiaowen, Q., Yahong, X., Changsheng, D., 2018. Tribological Behavior of Graphite Oxide Reinforced Polyethersulfone Composite under
Drying Sliding Condition. Polymer Composites, 39(7), 2320-2335.

3. Jianbing, C., Qiang, G., Zhengping, Z., Xianli, S., Xiaoming, W., Chunlai, D., 2013. Thermal, Crystalline, and Tribological Properties of PEEK/PEI/PES Plastics Alloys. Journal of Applied Polymer Science, 2220-2226.

4. Galal, S., Dilyus, C., Victor, T., Valerii, T. 2019. Effect of Formation Route on the Mechanical Properties of the Polyethersulfone Composites Reinforced with Glass Fibers. Polymers, 1364, 1-11.

5. Zhen, Z., Laizhou, S., Yulin, Y. 2015. Tribological Behavior of PolyethersulfoneReinforced Polytetrafluoroethylene Composite Under Dry Sliding Condition. Tribology International, 86, 17-27.

6. Yuan-Qing, L., Sen-Sen, D., Li-Yuan, L., Fei, L., De-Bo, L., Ze-Kun, Z., Hong-Mei, X., Ning, H., Shao-Yun, F., 2019. Synergistic Effects of Short Glass Fiber/Short Carbon Fiber Hybrids on the Mechanical Properties of Polyethersulfone Composites, Polymer Composites, 40(S2), 1725-1731.

7. Ye, Z., Yingshuang, S., Haibo, Z., Lianjun, D., Yunping, Z., Yuntao, H., Zhenghua, J., 2018. Friction and Wear Properties of Poly (Ether Sulfone) Containing Perfluorocarbon end Group. High Performance Polymers, 30(2), 247-253.

8. Mohit, S., Jayashree, B., Kuldeep, S., 2011. Studies for Wear Property Correlation for Carbon Fabric-Reinforced PES Composites. Tribology Letters, 43, 267-273.

9. Ze-Kun, Z., Sen-Sen, D., Fei, L., Hong-Mei, X., Yuan-Qing, L., Wei-Gang, Z., Ning, H., Shao-Yun, F., 2018. Mechanical and Tribological Properties of Short Glass Fiber and Short Carbon Fiber Reinforced Polyethersulfone Composites: A Comparative Study. Composites Communications, 8, 1-6.

10. Aravinthan, G., Kale, D.D., 2005. Blends of Poly (Ethylene Terephthalate) and Poly (Butylene Terephthalate). Journal of Applied Polymer Science, 98, 75-82.

11. Mohammadreza, N., Hazal, O., 2019. Development of PBT/Recycled-PET Blends and the Influence of Using Chain Extender. 
Journal of Polymers and the Environment, 27, 1404-1417.

12. Marek, S., 2004. Mechanical and Thermal Properties of PET/PBT Blends. Molecular Crystals and Liquid Crystals, 416(1), 209-215.

13. Hazer, S., Mehmet, Ö., Ayse, A., 2018. Characterization of Poly (Ethylene Terephthalate)/Poly (Butylene Terephthalate) Based Nanocomposites Reinforced with Reduced Graphene Oxide. $1^{\text {st }}$ International Symposium on Light Alloys and Composite Materials (ISLAC'18), 22-24 Mart, Karabük, 35-39.

14. Mohammed, A.B.R., David, A.S., Joao, M., 2018. Property/Morphology Relationships in SEBS-Compatibilized HDPE/Poly (Phenylene Ether) Blends. Macromolecules, 51(16), 6513-6523.

15. Edward, N.P., 2017. Poly (Phenylene Ether) Based Amphiphilic Block Copolymers. Polymers, 9(9), 433-457.

16. Do Kyun, K., Kwang Ho, S., Chong Min, K., Soon Man, H., Dong Wook, C., 2015. Characterization of Compatibilized Blends of Nylon 66/poly(2,6-dimethyl-1,4-phenylene ether)/high-impact Polystyrene Filled with Phosphinate-based Flame Retardants: Mechanical Property, Rheological Behavior and Flame Retardancy. Journal of Fire Sciences, 33(5), 339-357.

17. Alper, A., Teresa, M., Merve, A., Volker, A., 2020. Properties of Styrene-Maleic Anhydride Copolymer Compatibilized Polyamide 66/Poly (Phenylene Ether) Blends: Effect of Maleic Anhydride Concentration and Copolymer Content. Materials, 13, 1237-1253.

18. Lo, D., Chiang, C., Chang, F., 1997. Reactive Compatibilization of PET and PPE Blends by Epoxy Couplers. J. Appl. Polym. Sci. 65(4), 739-753.

19. Akkapeddi, M.K., 2014. Commercial Polymer Blends. In Polymer Blends Handbook, $2^{\text {nd }}$ ed.; Utracki, L.A., Wilkie, C.A., Eds.; Springer: Dordrecht, 1733-1883.

20. Harshavardhan, B., Ravishankar, R., Suresha, B., Srinivas, S., Arun, C.D.U., 2020. Influence of Short Carbon Fiber Content on Thermal Properties of Polyethersulfone Composites.
Materials Today: Proceedings, Available online 16 October 2020, In Press.

21. Yingjun, D., Peihong, C., Xujun, L., Tongsheng, L., 2009. Comparative Study of Tribological Properties of Polyphenylene Sulfide (PPS), Polyethersulfone (PES), and Polysulfone (PSU). Journal of Macromolecular Science, Part B: Physics, 48, 269-281.

22. Yan, S., Yahong, X., Yahui, H., Shoujun, W. 2020. Thermal, Mechanical and Tribological Properties of Sodium-montmorillonitenanoparticle-reinforced Polyethersulfone and Polytetrafluoroethylene Ternary Composites. Friction, 1-18.

23. Georgescu, C., Mihail, B., Lorena, D., 2014. Influence of Adding Materials in PBT on Tribological Behaviour. Materiale Plastice, 51(4), 350-354.

24. Yi-Lan, Y., Du-Xin, L., Gao-Jie, S., Ruo-Yun, L. Xin, D. 2016. Improvement in the Tribological Properties of Polyamide 6: Talc, Glass Fiber, Graphite and Ultrahigh-molecularweight Polyethylene. Journal of Thermoplastic Composite Materials, 29(4), 494-507.

25. Autay, R., Missaoui, S., Mars, J., Dammak, F., 2019. Mechanical and Tribological Study of Short Glass Fiber-reinforced PA 66. Polymers and Polymer Composites, 27(9), 587-596.

26. Anay, A., Kalyan, K.S., 2017. Friction and Wear Behaviour of Glass Fibre Reinforced Polymer Composite (GFRP) under Dry and Oil Lubricated Environmental Conditions. Materials Today: Proceedings, 4, 7285-7292.

27. Sudhir, K., Panneerselvam, K., 2015. Research on Tribological Behaviors of Pure and Glass Fiber Reinforced Nylon 6 Composites against Polymer Disc. Journal of Material Science and Mechanical Engineering (JMSME). 2(6), 24-28. 
